\title{
The Research for APG-12 Emulsifying Properties
}

\author{
Jigang Wang1, Sitong Chen1, Yongle Xin'1, Yong'an Wang² \\ ${ }^{1}$ EOR Key Laboratory of the Ministry of Education, Northeast Petroleum University, Daqing, China \\ ${ }^{2}$ Tarim Drilling Engineering Service Branch of CNPC Bohai Drilling Engineering Company Limited, \\ Korla, China \\ Email: wangjigang9999@163.com, 783669536@qq.com, 315463795@qq.com, anjuw123@163.com
}

Received 20 October 2014; revised 21 November 2014; accepted 11 December 2014

Copyright (C) 2015 by authors and Scientific Research Publishing Inc.

This work is licensed under the Creative Commons Attribution International License (CC BY).

http://creativecommons.org/licenses/by/4.0/

c) (i) Open Access

\section{Abstract}

Through determining and evaluating interfacial tension and emulsifying properties of dodecyl polyglucoside (APG-12), the results show that APG-12's performance is better than $C_{12}$ linear alkylbenzene sulfonate (LAS) and alkyl phenol polyoxyethylene ether (OP-10). In order to emulsify properties of APG-12, it is more stable when concentration is over $1.5 \mathrm{~g} / \mathrm{L}$. We studied the temperature and oil-water ratio has an effect on emulsifying property.

\section{Keywords}

\section{APG-12, Emulsifying Property, Surface Tension}

\section{Introduction}

Dodecyl polyglucoside (APG-12) is a kind of nonionic surfactant which is made of natural starch and vegetable oil derivatives. It has good surface activity, high alkali resistant ability and strong ability of degradation. APG-12 is the fastest growing products in the green surface active agent. In Huanxi ridge's crude oil, for example, this paper studied the emulsifying properties of APG-12.

\section{Experimental Section}

\subsection{Experimental Drugs and Laboratory Equipment}

Experimental drugs: dodecyl polyglucoside (APG-12), alkyl phenol polyoxyethylene ether (OP-10), $\mathrm{C}_{12}$ linear alkylbenzene sulfonate (LAS) and sodium chloride. the experimental oil is Huanxi Ridge crude oil.

Laboratory equipment: XSP-8CA type high power biological microscope, JPJ-300-type shear emulsifying 
mixers and BZY-2 automatic surface tension meter.

\subsection{Experimental Method}

\subsubsection{Emulsification Performance Test}

The surfactant placed into Huanxiling crude oil phase, with a blender at a rotational speed 500 r/min papering emulsion to be experiment.

1) Absorb the water-oil ratio 4:6 and 0.5\% APG-12 emulsion with a syringe. Drip it in a glass slide slowly. The finished water-oil emulsion in a glass slide was observed by microscope and record by camera. The types and sizes of emulsion were judged by analyzing the photos of water-oil emulsion.

2) Emulsion which consists of the surfactant preparation solution and oil was closed in test tubes. Put test tubes into constant $50^{\circ} \mathrm{C}$ water path pot and keep it $30 \mathrm{~min}$. During the constant temperature water bath, test tubes with stopper were shaved vigorously many times every 5 minutes. Make water and oil mixed fully. Put vertically test tubes into constant $50^{\circ} \mathrm{C}$ water path pot after the oil and water to mix. Emulsifying ability was judged by observing isolated water in $90 \mathrm{~min}$.

\subsubsection{Interfacial Tension Test}

Experiment measure surface tension by JMP2000 type surface tension meter. The method of surface tension is dissolve by APG-12 to different concentrations. The surface tension of different concentrations of APG-12 solution was determined at $25^{\circ} \mathrm{C}$. Draw concentration-surface tension curve with the commonly-used surfactants LAS and OP-10 contrast [1]-[6].

\section{Results and Discussion}

\subsection{Interface Activity and Emulsifying Capacity Evaluation}

The emulsion with microscope is observed. The picture is shown in Figure 1. We can see that the liquid's dispersed phase is oil; continuous phase is water. Emulsion is low viscosity oil-in-water emulsion.

The concentration-surface tension curve of different concentration surfactant is shown in Figure 2. We can see from the picture that when the increase of surfactant concentration surface tension reduces quickly, the interfacial activities of APG-12 are best in three kinds of surfactants. Surface tension can reach $27.0 \mathrm{mN} / \mathrm{m}$.

With the time extension, the dewatering amount increased gradually, dehydration rate was fast at first $30 \mathrm{~min}$. After 30 min, it became steady. By comparing the APG-12”s emulsifying ability with the other two surfactant, we can know that emulsifying ability of APG-12 is better than the OP-10 and LAS, excellent effect of emulsification. The experimental data are shown in Table 1.

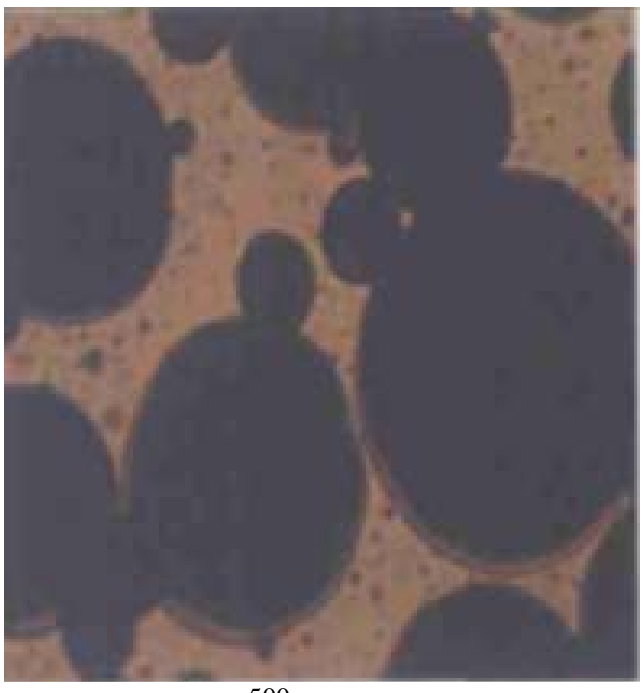

$500 \times$

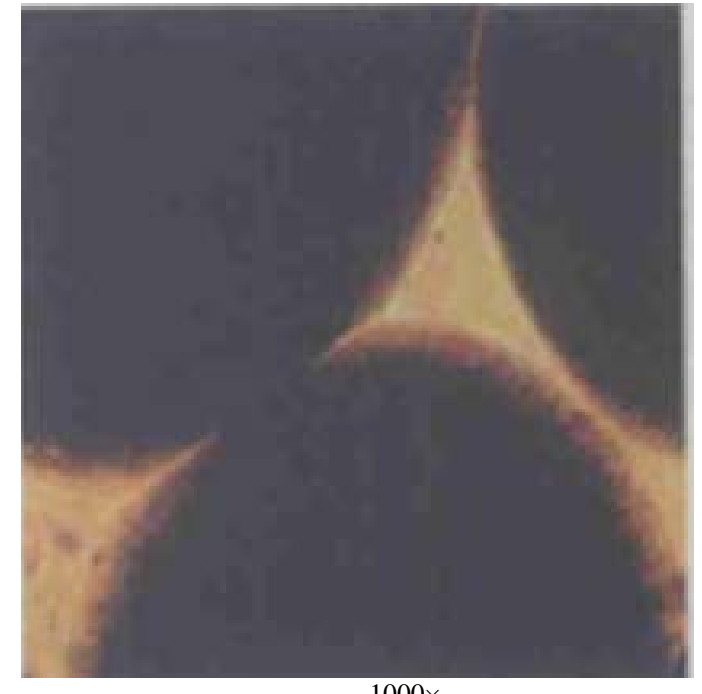

$1000 \times$

Figure 1. Microscopic photos of emulsion. 


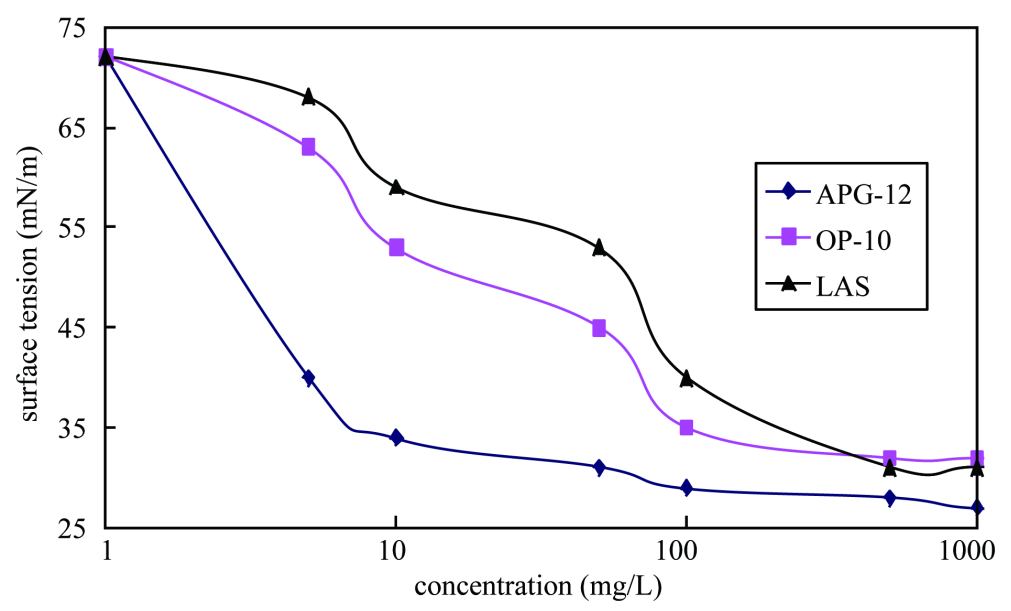

Figure 2. Surface tension of different products under different concentration.

Table 1. Dewatering of various products.

\begin{tabular}{ccccccc}
\hline \multirow{2}{*}{ Product } & \multicolumn{5}{c}{ dewatering amount $(\mathrm{mL})$} \\
\cline { 2 - 7 } & 0 min & 5 min & 15 min & 30 min & 60 min & 90 min \\
\hline APG-12 & 0 & 2.0 & 5.6 & 7.4 & 8.1 & 8.5 \\
OP-10 & 0 & 2.5 & 6.8 & 7.8 & 8.7 & 8.9 \\
LAS & 0 & 2.9 & 7.0 & 8.1 & 8.8 & 9.1 \\
\hline
\end{tabular}

\subsection{Influence of Surfactant Concentration on Emulsifying Property}

To investigate the effect of APG-12 concentration on emulsifying property, the volume of the water from emulsion was analyzed at different times by setting various concentrations of $0.5 \mathrm{~g} / \mathrm{L}, 1.0 \mathrm{~g} / \mathrm{L}, 1.5 \mathrm{~g} / \mathrm{L}, 2.0 \mathrm{~g} / \mathrm{L}$ and $3.0 \mathrm{~g} / \mathrm{L}$.

As can be seen from Figure 3, because density of the attached small droplets's APG-12 increased gradually, the arrangement was more intensive; intensity of interfacial film increased; emulsion system was more balanced and emulsifying power and stability were strengthened. When the concentration is $1.5 \mathrm{~g} / \mathrm{L}$, dewatering amount reduced rapidly; the formed emulsion system was more stable and the emulsifying power was stronger. When the concentration is higher, dewatering volume changed in a small range; emulsifying ability of system stopped increasing. The emulsion system has good emulsifying properties in concentration of $1.5 \mathrm{~g} / \mathrm{L}$.

\subsection{Influence of Surfactant Temperature on Emulsifying Property}

We measure dewatering volume of emulsion at different time under the temperature of $40^{\circ} \mathrm{C}, 50^{\circ} \mathrm{C}, 60^{\circ} \mathrm{C}$ to analyze its stability. Dewatering volume at different temperature is shown in Figure 4. With the increase of temperature, the dewatering volume increased. Temperature increment made the solubility of natural emulsifier in the dispersed phase of crude oil increase. It decreases the intensity of interfacial film adsorbed at the interface. In addition, thermal motion of molecules is enhanced with rising temperature. The dispersed phase collision and gather make the interface energy reduce. And then creaming happened.

\subsection{Influence of Oil-Water Ratio on Emulsifying Property}

In order to study the emulsifying properties of APG-12 affected by the ratio of oil to water, impact of emulsification ability was analyzed by setting different oil-water ratios (see Table 2). As can be seen from Table 2, dehydrated water from emulsion system became larger in volume as the ratio of oil to water decreased. When the oil-water ratio was relatively high, dewatering volume was small in system and the emulsifying ability was strong. When the oil-water ratio reached 4:6, dewatering volume was enhanced; the emulsion system was unstable and the emulsifying ability weakened. Because aqueous phase in system increased, overall surface area of oil 


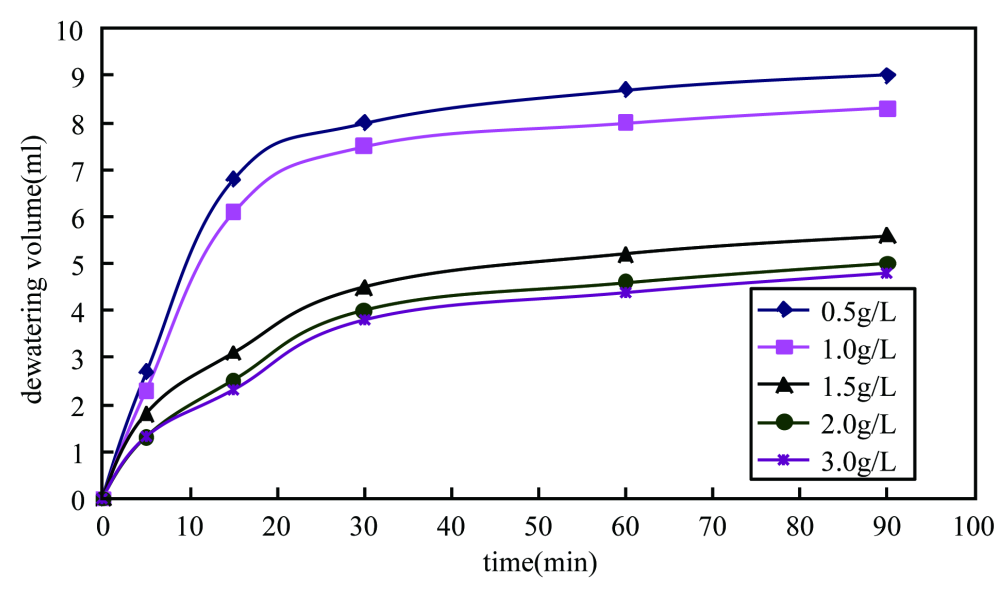

Figure 3. The effect of APG-12 concentration on emulsifying property.

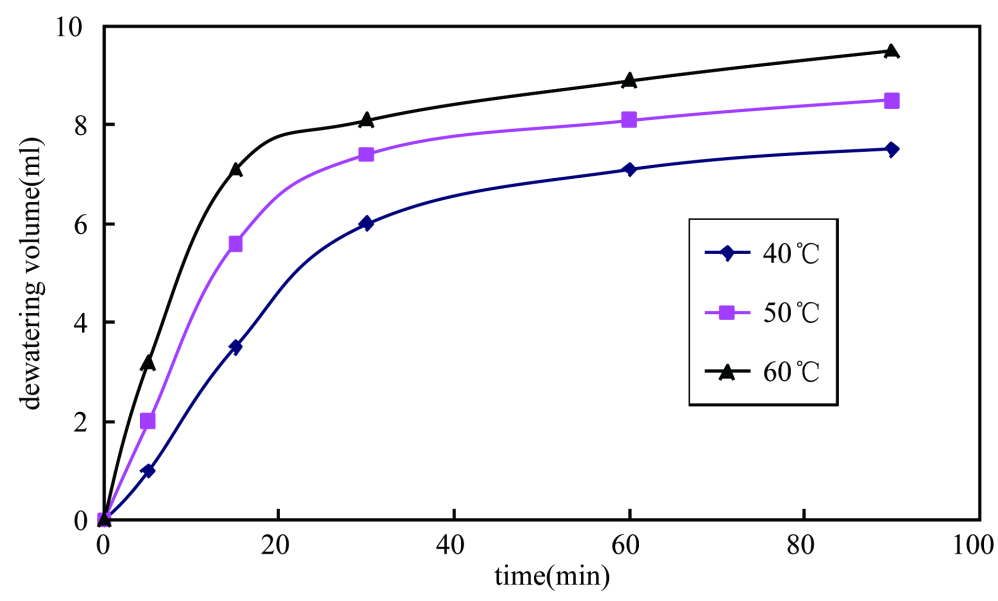

Figure 4. Influence of surfactant temperature on emulsifying property.

Table 2. Influence of oil-water ratio on emulsifying property.

\begin{tabular}{ccccccc}
\hline & \multicolumn{5}{c}{ Dewatering amount $(\mathrm{mL})$} \\
\cline { 2 - 7 } Oil-water ratio & 0 min & 5 min & 15 min & 30 min & 60 min & 90 min \\
\hline $7: 3$ & 0 & 0.8 & 2.1 & 2.9 & 3.4 & 3.7 \\
$6: 4$ & 0 & 1.9 & 3.1 & 4.0 & 4.5 & 4.9 \\
$5: 5$ & 0 & 2.1 & 3.3 & 4.7 & 5.6 & 6.1 \\
$4: 6$ & 0 & 3.8 & 7.4 & 8.9 & 9.3 & 10.0 \\
$3: 7$ & 0 & 4.7 & 8.4 & 10.3 & 11.6 & 12.1 \\
\hline
\end{tabular}

phase became large; APG-12 adhesion amount on interface unit area decreased and the emulsifying power and stability of emulsion system were reduced as the oil of water ratio decreased.

\section{Conclusion}

The emulsion becomes to more stable $\mathrm{O} / \mathrm{W}$ emulsion after adding surfactant. The higher the concentration is, the stronger emulsion stability is. Emulsification properties and economy at concentration of $1.5 \mathrm{~g} / \mathrm{L}$ are best. Emulsifying properties have outstanding performance at low temperature. As the temperature increases, the stability of the emulsion decreases. Oil-water ratio has a significant effect on the emulsifying property of the surfactant. 
As the ratio of water reduces, the stability of the emulsion decreases.

\section{Acknowledgements}

The project is supported by Heilongjiang Province Natural Science Foundation of Cationic Gemini Surfactant Study of Oil Displacement Technique. Fund No.: E201337.

\section{References}

[1] Xiao, C.L., Ding, W., Jing, G.L., et al. (2007) The Research on Synthesis and Performance of APG-12. Journal of Zhengzhou Grain College, 6, 76-85.

[2] Wu, M.H., Chen, H.Q., et al. (2000) The Profile Technology of Synthetize Alkyl Polyglycoside. Chemical Engineering, 25, 52-54.

[3] Yang, X.L. and Lu, W.Z. (2011) Study on the Stability of Crude Oil Emulsion. Oilfield Chemistry, 15, 87-96.

[4] Yu, N. (2004) Synthesis and Analysis of Physical and Chemical Properties of Alkyl Glucosides. Master's Thesis, Dalian University of Technology, Dalian, 20-34.

[5] Kiewert, E., Jesehke, P., Middelh, B. and Carrer, G. (2008) Cleaning Compositions for Hard Sues. Patent No. DE4210365.

[6] Sulek, M.W. and Wasilewski, T. (2005) Tribologieal Properties of Aqueous Solutions of Akyl Polyglueosides. Wear, 2, 193-204. 
Scientific Research Publishing (SCIRP) is one of the largest Open Access journal publishers. It is currently publishing more than 200 open access, online, peer-reviewed journals covering a wide range of academic disciplines. SCIRP serves the worldwide academic communities and contributes to the progress and application of science with its publication.

Other selected journals from SCIRP are listed as below. Submit your manuscript to us via either submit@scirp.org or Online Submission Portal.
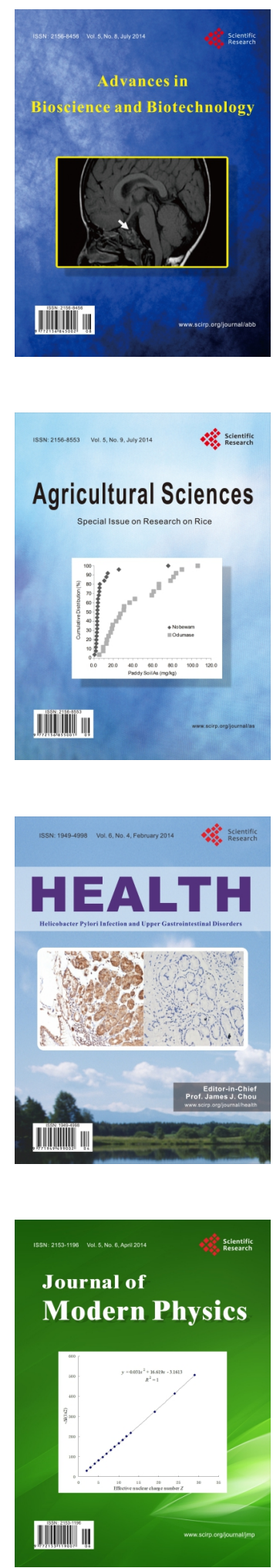
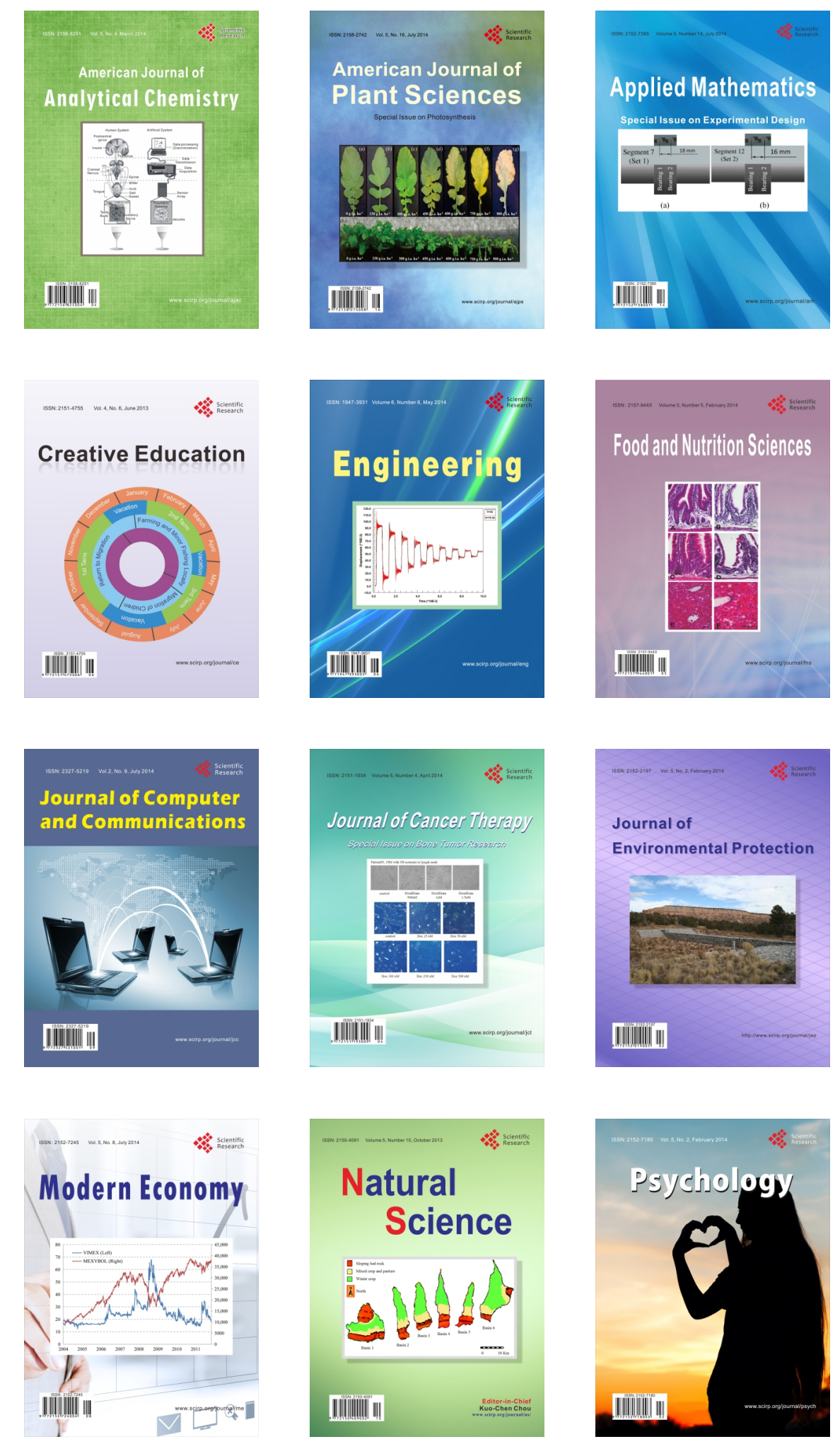